\title{
Orientação profissional para estudantes universitários com deficiências: conceitos, políticas e práticas
}

\author{
Professional guidance for tertiary students with disabilities: concepts, policies \\ and practices
}

Orientación profesional para estudiantes universitarios con deficiencias: conceptos, políticas y prácticas

\author{
Liz Amaral Saraiva Morgado \\ Doutoranda na Universidade Federal de São Carlos, São Carlos, São Paulo, Brasil. \\ saraiva_liz@hotmail.com \\ ORCID - https://orcid.org/0000-0002-8218-8179 \\ Leonardo Santos Amâncio Cabral \\ Professor doutor na Universidade Federal de São Carlos, São Carlos, São Paulo, Brasil. \\ prof.leonardocabral@gmail.com \\ ORCID - https://orcid.org/0000-0002-6154-3266
}

Recebido em 12 de agosto 2020

Aprovado em 19 de agosto de 2020

Publicado em 30 de setembro de 2020

\section{RESUMO}

As discussões inerentes às pessoas com deficiências que têm ingressado na Educação Superior e no mundo de trabalho incitam a necessidade de subsídios teóricos, políticos e práticos para a promoção de sua orientação acadêmico-profissional. Nesse sentido, a presente pesquisa objetivou: a) identificar produções científicas nacionais e internacionais que tiveram como foco temático a orientação profissional de estudantes universitários com deficiência; b) analisar a inter-relação entre os conteúdos das produções científicas e os documentos oficiais nacionais; e c) identificar e analisar elementos que possam constituir a elaboração e implantação de serviços de orientação profissional. Trata-se de uma revisão bibliográfica sistemática integrativa, valendo-se de descritores Thesaurus e operadores booleanos. Por meio do Portal de Periódicos Capes e Redalyc, foi possível a identificação, análise e discussões no âmbito das seguintes unidades temáticas: Documentos Norteadores Governamentais; Medidas Administrativas Institucionais; Estratégias DidáticoPedagógicas e Curriculares; Programas e Atividades de Extensão; Atores e Formação para a Orientação Profissional; Materiais e Instrumentos. A análise integrativa indicou que um programa adequado de orientação profissional para estudantes universitários com deficiência deva ser proposto sob uma perspectiva biopsicossocial, envolvendo as instituições de ensino e o mundo do trabalho, fomentando a autonomia, o reconhecimento de suas identidades, diferenças, expectativas profissionais e de vida, sob a perspectiva do lifelong learning.

Palavras-chave: Educação Especial; Educação Superior; mundo do trabalho. 
http://dx.doi.org/10.5902/1984686X53123

\section{ABSTRACT}

The discussions promoted by researchers and professionals that recognize the current challenges facing the higher education institutions and the world of work, when considering the need to raise elements inherent to the professional guidance of university students with disabilities. In order to contribute to the debate, this research had, as general objective, to identify, to gather, to systematize and to analyze scientific productions and documents that approach the referred subject. In this sense, through the method of systematic integrative bibliographical revision, we had as specific objectives: a) to identify national and international scientific productions that had the thematic focus the professional orientation of university students with disabilities; b) to analyze the inter-relation between the contents of scientific productions and national official documents (legal diplomas, policies and government programs); and c) to identify and analyze elements that may constitute the preparation and implementation of professional guidance services. This is an integrative systematic bibliographic review, using Thesaurus descriptors and Boolean operators. Through the Capes and Redalyc Journal Portal, it was possible to identify, analyze and discuss the following thematic units: Government Guiding Documents; Institutional Administrative Measures; Didactic-Pedagogical and Curricular Strategies; Extension Programs and Activities; Actors and Training for Vocational Guidance; Materials and Instruments. The integrative analysis indicated that an adequate professional guidance program for university students with disabilities should be proposed from a biopsychosocial perspective, involving educational institutions and the world of work, promoting autonomy, the recognition of their identities, differences, professional expectations and from the perspective of lifelong learning.

Keywords: Special Education; Higher Education; world of work.

\section{RESUMEN}

El espectro de discusiones fomentadas por investigadores y profesionales que reconocen los actuales desafíos que se presentan a las Instituciones de Enseñanza Superior y al mundo del trabajo, cuando se considera la necesidad de suscitar elementos inherentes a la orientación profesional de estudiantes universitarios con discapacidad. Con vistas a contribuir con el debate, esa investigación tuvo como objetivo general identificar, reunir, sistematizar y analizar producciones científicas y documentos que aborden la referida temática. En ese sentido, por medio del método de revisión bibliográfica sistemática integrativa, tuvimos como objetivos específicos: a) identificar producciones científicas nacionales e internacionales que tuvieron como foco temático la orientación profesional de estudiantes universitarios con discapacidad; b) analizar la inter-relación entre los contenidos de las producciones científicas y los documentos oficiales nacionales (diplomas legales, políticas y programas gubernamentales); e c) identificar y analizar elementos que puedan constituir la elaboración e implantación de servicios de orientación profesional Se trata de una revisión bibliográfica sistemática integradora, que utiliza descriptores de tesauro y operadores booleanos. A través del Portal de Revistas Capes y Redalyc, fue posible identificar, analizar y discutir las siguientes unidades temáticas: Documentos Orientadores de Gobierno; Medidas administrativas institucionales; Estrategias DidácticoPedagógicas y Curriculares; Programas y actividades de extensión; Actores y Formación para la Orientación Profesional; Materiales e instrumentos. El análisis integrador indicó que debe proponerse un adecuado programa de orientación profesional para estudiantes universitarios con discapacidad desde una perspectiva biopsicosocial, involucrando a las instituciones educativas y al mundo laboral, promoviendo la autonomía, el reconocimiento 
http://dx.doi.org/10.5902/1984686X53123

de sus identidades, diferencias, expectativas profesionales y desde la perspectiva del aprendizaje permanente.

Palabras clave: Educación Especial; Educación Superior; mundo del trabajo.

\section{Introdução}

As políticas educacionais dos diversos países membros da Organização das Nações Unidas - ONU têm direcionado seus dispositivos à luz da perspectiva da aprendizagem ao logo da vida [lifelong learning], da cidadania ativa ${ }^{1}$ para o desenvolvimento pessoal e da empregabilidade (DEPARTMENT OF EDUCATION AND SCIENCE, 2000; THE ECONOMIST, 2017).

Este direcionamento está atrelado, ainda, às intenções de órgãos internacionais como a Organização Internacional do Trabalho - OIT, a Organização das Nações Unidas para a Educação, a Ciência e a Cultura - UNESCO e o Banco Mundial [World Bank Group] (CABRAL; SANTOS; MENDES, 2018).

No Brasil, sobretudo nas últimas duas décadas, essas premissas têm incitado históricos movimentos nacionais e internacionais de cunho político, social, educacional, ideológico, econômico e cultural. Consequentemente, observa-se um processo de democratização do acesso das minorias político-sociais nas diversas esferas da sociedade, inclusive nas Instituições da Educação Superior (IES) ${ }^{2}$ e no mundo do trabalho.

Particularmente no que tange as pessoas com deficiências ${ }^{3}$, o mais recente Censo da Educação Superior indicou um total de 14.293 (0,7\%) matrículas em IES públicas e, no mundo do trabalho, a empregabilidade de diplomados com deficiências não chega a 0,2\% em trabalhos formais (INEP, 2019; MINISTÉRIO DA ECONOMIA, 2019).

Esse cenário deveria incitar as IES brasileiras a promoverem não apenas oportunidades de ingresso dessa população na Educação Superior, na qual, predominantemente, ocorrem via políticas de ações afirmativas e sistemas de reserva de vagas. A elas importa que sejam somadas iniciativas que subsidiem a trajetória acadêmica, a formação profissional, a diplomação e a transição dos estudantes com deficiências ao mundo do trabalho (CABRAL, 2013; CASTRO; AMARAL; BORGES, 2017).

Urge, portanto, a necessidade das comunidades acadêmico-científicas em apresentarem debates fundamentados teórica e metodologicamente, não apenas a respeito de orientação vocacional ou de orientação laboral ${ }^{4}$, mas no espectro do que compreendemos como orientação profissional. 
http://dx.doi.org/10.5902/1984686X53123

A orientação profissional sofreu diversas influências e ressignificações em seus conceitos e aplicabilidades entre as últimas décadas do século XIX e o início do século XX.

Foi em 1924 que, segundo Nérice (1992), o primeiro programa de orientação profissional direcionado a estudantes foi implementado no Liceu de Artes e Ofícios de São Paulo. Nas décadas subsequentes, medidas similares foram adotadas por outras instituições e, gradativamente, reconhecidas pelo poder público ${ }^{5}$.

Somente na década de 1970, porém, por meio da Lei de Diretrizes e Bases para o ensino de $1^{\circ}$ e $2^{\circ}$ graus (BRASIL, 1971), que a necessidade de programas de orientação profissional em contextos educacionais foi timidamente mencionada. Ainda assim, foi apenas após 25 anos que a legislação educacional brasileira determinou que os conteúdos curriculares da educação básica observassem a "orientação para o trabalho" (BRASIL, 1996).

A comunidade científica, por sua vez, apenas recentemente vem debruçando-se sobre a temática (ALFREDO, 2006; AGUIAR; BOCK; OZELLA, 2009; SOARES, 2009; LEHMAN, 2010; GONZÁLEZ; GARCIA, 2012; PINTO; CASTANHO, 2012; CABRAL, 2013; CHIAVENATO, 2014; CAVALCANTE; RODRIGUES; NETTO, 2015). Fundamentalmente, os referidos autores têm sugerido a constituição de programas de orientação profissional com atividades que envolvam cooperativamente o estudante, as equipes multidisciplinares e o mundo do trabalho.

Em prática, os estudos indicam: a) a realização de avaliações processuais (individuais e em grupos), a curto, médio e longo prazo; b) a identificação de experiências acadêmicoprofissionais prévias; c) a compreensão de seus contextos familiares, sociais, culturais e econômicos; d) o desenvolvimento de estratégias para ações críticas construtivas, de autoconhecimento e de autogestão de competências; e) o planejamento e a tomada consciente de decisões para a consolidação de suas expectativas de vida; e f) a aproximação entre as oportunidades de formação e as condições do mundo do trabalho.

Contudo, ao considerar os estudantes universitários com deficiências no âmbito de atividades de orientação profissional, questiona-se: seriam necessárias diferenciações no processo de planejamento e desenvolvimento de suas respectivas trajetórias acadêmicas e profissionais? Como construir o envolvimento das instituições empregadoras nos serviços de orientação acadêmica e profissional?

À luz dessas inquietações, a presente pesquisa objetivou identificar, reunir, sistematizar e analisar, sob a perspectiva integrativa, documentos (diplomas legais, 
políticas e programas governamentais) e produções científicas nacionais e internacionais que possam apresentar elementos que subsidiem proposições de programas de orientação profissional voltados a estudantes universitários com deficiências.

Transversalizando as referidas intenções está a necessidade de as IES brasileiras reconhecerem as identidades, as competências e as diferenças desse alunato em suas respectivas trajetórias acadêmicas, de diplomação e de transição para o mundo do trabalho, sob a perspectiva cooperativa e da acessibilidade.

\section{Desenvolvimento}

No espectro dos métodos de revisão da literatura, a presente pesquisa foi desenvolvida à luz da abordagem de revisão bibliográfica sistemática integrativa ${ }^{6}$. Inspirada na Prática Baseada em Evidências e coadunando com a Gestão Baseada em Evidências, conforme indicam Botelho, Cunha e Macedo (2011), esse método tem sido incorporado atualmente como importante ferramenta de pesquisa nas Ciências Sociais Aplicadas (Figura 1).

Figura 1 - Fluxograma indicativo dos tipos de revisão da literatura

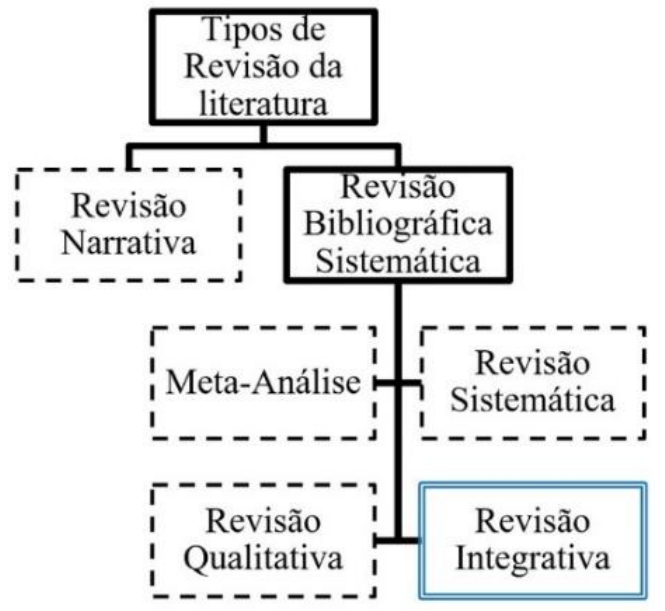

Fonte: Elaborado pelos autores, adaptado de Whitemore; Knafl (2005).

Essa abordagem tem por finalidade reunir e sintetizar, de maneira sistemática e ordenada, elementos trazidos em documentos oficiais, em métodos e em resultados de pesquisas, de modo a traçar um panorama contextualizado sobre sua produção científica e suas eventuais lacunas, dando suporte para a tomada de decisões e para a melhoria das práticas (WHITEMORE; KNAFL, 2005; BROOME, 2006; ROTHER, 2007; MENDES; SILVEIRA; GALVÃO, 2008; BOTELHO; CUNHA; MACEDO, 2011). 
http://dx.doi.org/10.5902/1984686X53123

Nesse sentido, o presente estudo foi realizado em seis etapas principais de execução, a saber:

1a Etapa - definição das estratégias de busca, dos descritores e das bases de dados: o levantamento da produção científica foi realizado mediante busca eletrônica ${ }^{7}$, em bases de dados indexadas primárias e secundárias, nas áreas da Psicologia, Medicina, Ciências Sociais e Educação ${ }^{8}$. Contudo, os descritores adotados e suas respectivas combinações identificaram artigos científicos apenas nos portais da CAPES e do REDALYC (Quadros 1 e 2).

Quadro 1 - Descritores Utilizados no Portal de periódicos Capes e número de artigos científicos identificados

\begin{tabular}{|c|c|c|}
\hline Descritores & $\begin{array}{c}\text { Resultado } \\
\text { inicial }\end{array}$ & Resultado Final \\
\hline orientação profissional AND deficiência & 51 & 2 \\
\hline orientação profissional AND necessidades especiais & 9 & 1 \\
\hline orientação profissional AND inclusão social & 17 & 0 \\
\hline orientação profissional de universitários com deficiência & 220 & 1 \\
\hline professional orientation AND disability & 137 & 0 \\
\hline professional orientation AND handicap & 30 & 0 \\
\hline professional orientation AND special population & 1 & 0 \\
\hline career guidance AND disability & 373 & 3 \\
\hline TOTAL & 838 & 7 \\
\hline
\end{tabular}

Fonte: Elaborado pelos autores (2020).

Quadro 2 - Descritores base de dados Redalyc e número de artigos científicos identificados

\begin{tabular}{|c|c|c|}
\hline Descritores & $\begin{array}{l}\text { Resultado } \\
\text { inicial }\end{array}$ & $\begin{array}{c}\text { Resultado } \\
\text { Final }\end{array}$ \\
\hline "orientação profissional" AND "deficiência" & 193 & 6 \\
\hline "orientação profissional" AND "necessidades especiais" & 42 & 3 \\
\hline “orientação profissional” AND “inclusão social” & 64 & 4 \\
\hline "orientação profissional de universitários com deficiência" & 220 & 1 \\
\hline "professional orientation" AND "disability" & 490 & 0 \\
\hline “professional orientation" AND "handicap" & 139 & 0 \\
\hline "professional orientation" AND "special population" & 0 & 0 \\
\hline "career guidance" AND "disability" & 16 & 1 \\
\hline "orientación professional" AND “discapacidad" & 1078 & 4 \\
\hline $\begin{array}{c}\text { "orientación professional" AND "universitarios con } \\
\text { discapacidad" }\end{array}$ & 3935 & 4 \\
\hline TOTAL & 6177 & 23 \\
\hline
\end{tabular}

Fonte: Elaborado pelos autores (2020).

2- Etapa - Estabelecimento dos critérios de inclusão e exclusão: com base nos problemas e objetivos da pesquisa, nos títulos e resumos dos estudos identificados e nos critérios de inclusão, foram explorados e selecionados: (a) aqueles publicados na 
modalidade de artigo científico e (b) os que investigaram especificamente a orientação profissional de estudantes universitários com deficiência. No mesmo processo, foram adotados como critérios de exclusão: (a) a falta de relação com o tema da presente pesquisa; (b) publicações repetidas entre as bases de dados; (c) não estar disponível na íntegra nas bases de dados selecionadas e (d) estudos de revisão sistemática.

Conforme indicado por Melnyk et al. (2010), foi realizada uma leitura de todos os artigos considerados elegíveis para inclusão na revisão e análise criteriosa das informações veiculadas para, então, conhecer o número final de estudos a serem analisados (Figura 2).

Figura 2 - O processo de Revisão Bibliográfica Sistemática Integrativa

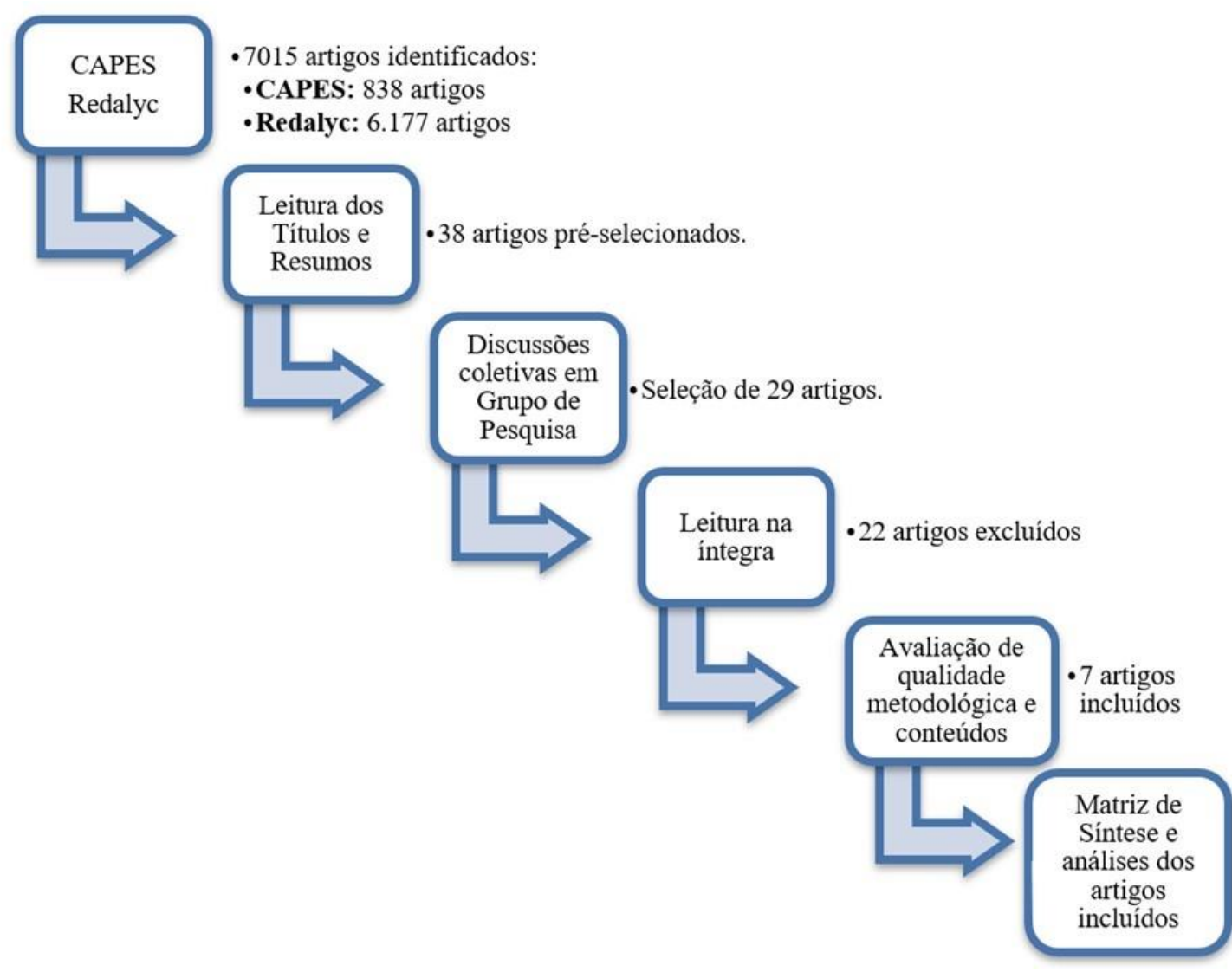

Fonte: Elaborado pelos autores (2020).

\section{3a Etapa - Identificação dos estudos pré-selecionados e selecionados: como} observado na Figura 2, o número inicial de artigos foi alto (7.015 produções), se comparado ao número final (sete produções). Tamanha diferença deve-se ao fato de a maior parte das pesquisas identificadas serem especificamente da área da enfermagem e não condizerem com a temática central da presente pesquisa. Outro fator importante a ser destacado foi que, dentre os sete artigos identificados, somente um era nacional, em língua portuguesa, 
http://dx.doi.org/10.5902/1984686X53123

e os demais eram internacionais (um em língua inglesa e cinco em língua espanhola ${ }^{9}$ ). No que tange ao método das pesquisas, foram identificados um estudo documental, uma pesquisa-ação, um estudo de caso exploratório-descritivo, dois estudos descritivos e dois estudos de caso (Quadro 3).

Quadro 3 - Trabalhos selecionados para análise

\begin{tabular}{|c|c|c|c|c|}
\hline Título & Autor (es) & Revista & Ano & $\begin{array}{l}\text { Tipo de } \\
\text { Estudo }\end{array}$ \\
\hline $\begin{array}{l}\text { La inclusión social y laboral de las } \\
\text { personas con discapacidad } \\
\text { intelectual mediante los } \\
\text { programas de empleo com apoyo: } \\
\text { un reto para la orientación. }\end{array}$ & $\begin{array}{l}\text { Inmaculada Egido } \\
\text { Gálvez; Rosario } \\
\text { Cerrillo Martín; } \\
\text { Asunción Camina } \\
\text { Durantes }\end{array}$ & $\begin{array}{l}\text { Revista } \\
\text { Española de } \\
\text { Orientación y } \\
\text { Psicopedagogía }\end{array}$ & 2009 & Descritivo \\
\hline $\begin{array}{l}\text { Atención y orientación a los } \\
\text { estudiantes con discapacidad en } \\
\text { la UNED. }\end{array}$ & $\begin{array}{l}\text { José Rafael } \\
\text { Guillamón; Víctor } \\
\text { M. Rodríguez }\end{array}$ & $\begin{array}{l}\text { Revista } \\
\text { Española de } \\
\text { Orientación y } \\
\text { Psicopedagogía }\end{array}$ & 2010 & Documental \\
\hline $\begin{array}{l}\text { Re-thinking support: the hidden } \\
\text { school-to-work challenges for } \\
\text { individuals with special needs. }\end{array}$ & Sonali Nag & $\begin{array}{l}\text { International } \\
\text { Journal on } \\
\text { Educational and } \\
\text { Vocational } \\
\text { Guidance }\end{array}$ & 2011 & $\begin{array}{l}\text { Pesquisa - } \\
\text { ação }\end{array}$ \\
\hline $\begin{array}{l}\text { Transición al mundo laboral de } \\
\text { estudiantes universitarios con } \\
\text { discapacidad: experiencia de um } \\
\text { programa formativo. }\end{array}$ & $\begin{array}{l}\text { Maria Tamara } \\
\text { Polo Sánchez; } \\
\text { Maria Dolores } \\
\text { López Justicia }\end{array}$ & $\begin{array}{l}\text { Revista } \\
\text { Española de } \\
\text { Orientación y } \\
\text { Psicopedagogía }\end{array}$ & 2011 & $\begin{array}{l}\text { Estudo de } \\
\text { Caso }\end{array}$ \\
\hline $\begin{array}{l}\text { Relación entre el desarrollo } \\
\text { vocacional eficaz y los factores de } \\
\text { elección en titulados } \\
\text { universitarios con discapacidad } \\
\text { activos laboralmente: un estudio } \\
\text { preliminar. }\end{array}$ & $\begin{array}{l}\text { María Ángeles } \\
\text { Segura García; } \\
\text { José Manuel } \\
\text { Martínez Vicente; } \\
\text { Isabel García } \\
\text { Martínez }\end{array}$ & $\begin{array}{l}\text { Revista } \\
\text { Española de } \\
\text { Orientación y } \\
\text { Psicopedagogía }\end{array}$ & 2015 & Descritivo \\
\hline $\begin{array}{l}\text { Orientação acadêmica e } \\
\text { profissional dos estudantes com } \\
\text { deficiência nas universidades } \\
\text { italianas }\end{array}$ & $\begin{array}{l}\text { Leonardo Santos } \\
\text { Amâncio Cabral; } \\
\text { Enicéia } \\
\text { Gonçalves } \\
\text { Mendes; Lucia de } \\
\text { Anna }\end{array}$ & $\begin{array}{l}\text { Revista Ibero- } \\
\text { Americana de } \\
\text { Estudos em } \\
\text { Educação }\end{array}$ & 2015 & $\begin{array}{l}\text { Estudo de } \\
\text { caso } \\
\text { exploratório - } \\
\text { descritivo }\end{array}$ \\
\hline $\begin{array}{l}\text { La acción tutorial como } \\
\text { acompañamiento en el alumnado } \\
\text { universitário con discapacidad: } \\
\text { hacia una educación inclusiva. }\end{array}$ & $\begin{array}{l}\text { Gonzalo Lorenzo } \\
\text { Lledó; Asunción } \\
\text { Lledó Carreres; } \\
\text { Alejandro } \\
\text { Lorenzo Lledó; } \\
\text { Graciela Arráez } \\
\text { Vera }\end{array}$ & $\begin{array}{l}\text { International } \\
\text { Journal of } \\
\text { Developmental } \\
\text { and Educational } \\
\text { Psychology }\end{array}$ & 2017 & $\begin{array}{l}\text { Estudo de } \\
\text { Caso }\end{array}$ \\
\hline
\end{tabular}

Fonte: Elaborado pelos autores (2020).

4ª Etapa - Categorização dos Estudos Selecionados: nessa etapa, foi elaborada uma matriz de síntese, contendo as principais informações ${ }^{10}$ do artigo. Em seguida, foram criadas categorias de análise: 1) Documentos Norteadores; 2) Medidas Administrativas; 3) 
http://dx.doi.org/10.5902/1984686X53123

Estratégias Didático-Pedagógicas e Curriculares; 4) Atividades de Extensão; 5) Atores Envolvidos e 6) Instrumentos e Materiais.

5ª e 6⿳a Etapas - Análise, interpretação, discussão e apresentação da síntese do conhecimento sobre a temática: essas etapas foram pormenorizadas nos resultados e discussões do presente estudo sob a perspectiva da análise integrativa e, com base em sínteses descritivas, foram reunidas propostas para estudos futuros (GANONG, 1987; MENDES; SILVEIRA; GALVÃO, 2008; MELNYK et al., 2010).

A revisão sistemática integrativa da literatura sobre orientação profissional voltada a estudantes universitários com deficiências indicou a abordagem de três temas principais pela comunidade científica: 1) implementação, avaliação de programas e transição para o mundo do trabalho (GÁLVEZ; MARTíN; DURANTES, 2009; GUILLAMÓN; RODRÍGUEZ, 2010; NAG, 2011; CABRAL; MENDES; DE ANNA, 2015; LLEDÓ; CARRERES; LLEDÓ; VERA, 2017); 2) treinamento (SÁNCHEZ; JUSTICIA, 2011); e 3) escolha vocacional (GONZÁLEZ; GARCIA, 2012).

Cumpre destacar, porém, que, para além do reduzido número de produções sobre a temática, nenhuma delas é fruto de estudos realizados sobre o contexto brasileiro. Esse dado sustenta a necessidade de a orientação profissional voltada a pessoas com deficiências, particularmente que sejam estudantes das IES brasileiras, ser objeto de estudos nacionais.

Nesse cenário, ao debruçar-se para identificar, reunir, sistematizar e analisar os elementos que emergiram das referidas produções científicas foi possível, à luz da análise integrativa, organizá-los, explorá-los e discuti-los no âmbito das seguintes unidades temáticas:

\section{a) Documentos Norteadores Governamentais}

Ainda que os artigos mencionassem documentos governamentais e institucionais de seus respectivos países relacionados ao ingresso e à permanência dos estudantes com deficiências nas IES, apenas um (CABRAL et al., 2015) mencionava especificamente sobre o planejamento, a elaboração e a implementação de programas orientação profissional para esse alunato na realidade italiana (Legge quadro nํ104, 05 febbraio 1992).

No Brasil, apesar da promulgação da LDB de 1996, até o momento, não foram criadas políticas específicas relacionadas à efetiva orientação profissional de estudantes 
http://dx.doi.org/10.5902/1984686X53123

universitários com deficiência. Entretanto, o Decreto № 3.298 (1999) aborda o termo inserção laboral, em seu Artigo 35, apresentando suas respectivas modalidades:

\begin{abstract}
I - colocação competitiva: processo de contratação regular, nos termos da legislação trabalhista e previdenciária, que independe da adoção de procedimentos especiais para sua concretização, não sendo excluída a possibilidade de utilização de apoios especiais; II - colocação seletiva: processo de contratação regular, nos termos da legislação trabalhista e previdenciária, que depende da adoção de procedimentos e apoios especiais para sua concretização; III - promoção do trabalho por conta própria: processo de fomento da ação de uma ou mais pessoas, mediante trabalho autônomo, cooperativado ou em regime de economia familiar, com vista à emancipação econômica e pessoal. (BRASIL, 1999).
\end{abstract}

Sendo assim, pode-se inferir que, ainda que se tenham diversos dispositivos legais que permeiam a inclusão das pessoas com deficiência em todos os níveis de ensino e que, particularmente, respaldam o direito de acesso, permanência, diplomação e reconhecimento dessa população no Ensino Superior ${ }^{11}$ e no mundo do trabalho ${ }^{12}$, não foram identificadas políticas específicas que resguardassem o direito dessa população ter à disposição serviços de orientação profissional no contexto universitário.

\title{
b) Medidas Administrativas Institucionais
}

Guillamón e Rodríguez (2010) indicaram medidas como: a isenção de pagamento por serviços acadêmicos aos estudantes com deficiência; ações para a acessibilidade e a criação de uma unidade dedicada às questões relacionadas à deficiência e ao voluntariado. Outras medidas foram apresentadas por Cabral et al. (2015), tais como a possível articulação entre a universidade e as unidades locais de saúde e associações, além da possibilidade de envolverem agências locais facilitadoras de mediação com o mundo do trabalho.

No âmbito das IES públicas brasileiras, contudo, a produção científica não indicou iniciativas interdisciplinares e intersetoriais que propiciassem 0 desenvolvimento profissional orientado, considerando as especificidades de estudantes universitários com deficiência tanto na universidade quanto no contexto do mundo do trabalho.

\section{c) Estratégias Didático-Pedagógicas e Curriculares}

Para além das disciplinas teóricas oferecidas pelos cursos de graduação em nível superior, pode-se considerar, assim como indicaram Guillamón e Rodríguez (2010), a importância das atividades práticas e estágios curriculares, os quais podem resultar em um 
impacto positivo tanto sobre o próprio estudante quanto sobre o possível contratante. Particularmente no que tange à orientação profissional dos estudantes universitários com deficiência, de acordo com Cabral et al. (2015, p. 622), o currículo pode prever, especificamente:

a colaboração entre os Serviços de Estágios e Colocação no Mercado de Trabalho e o de Tutoria Especializada da Universidade, a fim de facilitar o encontro entre a demanda e a oferta de trabalho, fornecendo, inclusive, orientação no momento da escolha e durante a formação profissional, principalmente por meio de estágios.

Assim, ao pensar em acessibilidade, deve-se considerar que a acessibilidade curricular é fundamental, sobretudo quando se consideram as atividades práticas e estágios, os quais se configuram como momentos fundamentais no processo de formação e orientação profissional.

\section{d) Programas e Atividades de Extensão}

Sánchez e Justicia (2011) versaram sobre os impactos positivos de um programa de treinamento, intitulado "Da Universidade ao Mundo do Trabalho: estratégias e recursos para o acesso ao emprego", dividido em módulos focados em aconselhamento e formação nas áreas deficitárias detectadas, tais como: aumento da autoestima e autoconfiança, gestão de situações sociais conflituosas e busca de emprego.

Gálvez, Martín e Durantes (2009), por sua vez, apresentaram os resultados de programas específicos de orientação profissional voltados para as pessoas com deficiência intelectual, indicando um importante envolvimento dos próprios estudantes nos processos previstos, com indícios de melhorias nas esferas pessoal e profissional, além da tendência de resposta às demandas do mundo do trabalho e às lacunas de formação dos próprios estudantes.

Nesse sentido, tende-se a inferir que as atividades e programas de extensão podem favorecer a construção de uma perspectiva interdisciplinar que desperte tanto o interesse de empregadores quanto a ressignificação das estratégias e ações de formação ofertadas pelas IES brasileiras.

\section{e) Atores e Formação para a Orientação Profissional}

Segundo os artigos analisados, além dos próprios estudantes universitários com deficiência, foi plausível reunir as seguintes figuras, que puderam ser envolvidas na função 
de avaliar e analisar o perfil acadêmico de cada estudante, a saber: conselheiros de carreira da universidade ou counselor (NAG, 2011; GÁLVEZ; MARTíN; DURANTES, 2009), os tutores empresariais $^{13}$, os professores, os familiares (CABRAL et al., 2015) e os tutores em pares (LLEDO et al., 2017).

Assim, ainda que exista uma ampla gama de atores nesse processo, em nenhum momento os autores indicaram a formação exigida para exercer a função de orientador profissional, podendo ser professores, psicólogos, técnicos administrativos, entre outros. Sobre isso, Lisboa (2002) observou que a formação para atuação específica junto a esse público ainda se desenvolve timidamente nas diversas realidades.

No Brasil, Melo-Silva (2003) ressaltou que tanto os cursos universitários quanto os cursos de especialização oferecidos na área da Orientação Profissional, Educação e Desenvolvimento de Carreira eram insuficientes para capacitar os profissionais em tantos saberes, 0 que requer equipes multidisciplinares e interdisciplinares para 0 desenvolvimento das competências centrais e específicas, considerando-se cada contexto.

Soma-se a esse fato a advertência de Melo-Silva, Lassance e Soares (2004) que indicaram a ausência de regulamentação ou de definição de critérios de qualificação do orientador profissional na realidade brasileira, sugerindo que a Assembleia Geral da Associação Brasileira de Orientação Profissional apresentasse propostas nesse sentido.

\section{f) Materiais e Instrumentos}

O estudo de Gálvez et al. (2009) indicou a utilização de questionários para coletar informações relevantes sobre a análise do programa formativo por parte dos alunos, pais e professores. Ambiel e Polli (2011) recomendaram alguns outros instrumentos, a saber: 0 Questionário de Busca Autodirigida [SDS]; a Escala de Aconselhamento Profissional [EAP]; a Bateria de Provas de Raciocínio [BPR-5]; e o Teste de Fotos de Profissões [BBT-Br].

Em relação ao funcionamento de um programa de orientação profissional, o que se encontrou foram apenas pistas, tal como apresentado por Cabral et al. (2015), as quais indicaram que a orientação profissional poderia dividir-se em nove fases: (1) avaliação do estudante; (2) encontro entre a oferta e a demanda; (3) preparação para a apresentação à empresa; (4) apresentação e definição dos papéis ao interno da empresa; (5) sensibilização e colaboração entre os atores; (6) desenvolvimento do projeto; (7) realização das atividades; (8) monitoramento e (9) manutenção ou reformulação das atividades e das funções. 
Importa ressaltar que, em todos os estudos, chamou atenção o fato de o universitário com deficiência não ter sido apresentado como o protagonista do processo de orientação profissional e, sim, como parte coadjuvante de toda a engrenagem que o movimenta, envolvendo, inclusive, diversos profissionais, a família (quando necessário) e a própria comunidade (Figura 3).

Figura 3 - Representação Gráfica, em Fluxograma, resultante da Análise Integrativa sobre Orientação Profissional de Estudantes Universitários com deficiência

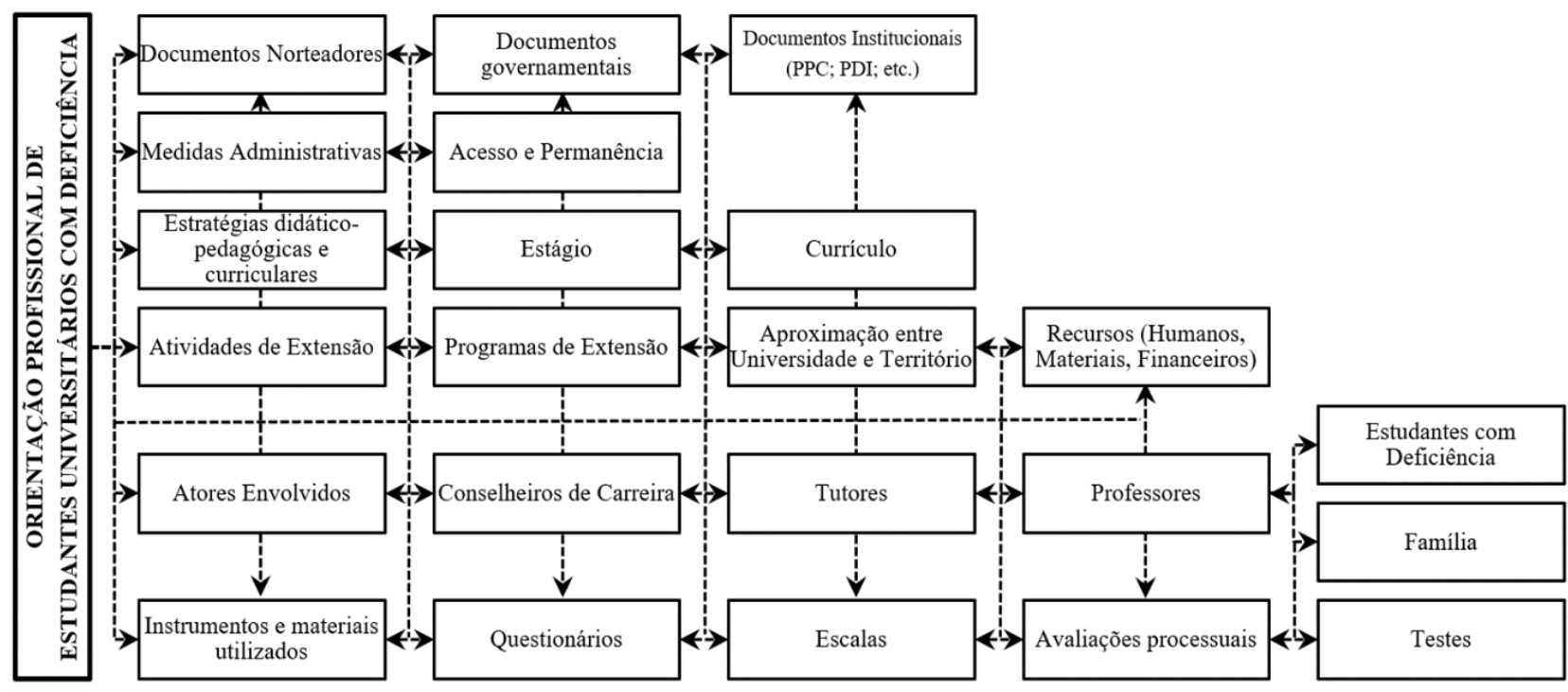

Fonte: Elaborado pelos autores (2020).

Conforme apresentado e discutido, pode-se inferir que a análise integrativa permitiu a identificação de possíveis elementos, cujas inter-relações dinâmicas poderão (pro)mover programas de Orientação Profissional na perspectiva biopsicossocial e da acessibilidade.

\section{Transclusões}

Não seria coerente que esse espaço fosse intitulado de "Considerações Finais" e, tampouco, de "Conclusões", como se fosse possível finalizar, encerrar, ou deter as reflexões provocadas em confines, até por ser um tema ainda não presente nas discussões da comunidade científica brasileira. Compreendemos que estamos mais próximos de transclusões, tais como janelas de conhecimentos que se abrem sucessivamente para outras (NELSON, 1965).

Essas são provocações que convidam as comunidades científicas e acadêmicas, sobretudo das áreas das Ciências da Educação, Ciências Sociais, Ciências Políticas, Ciências da Saúde, Ciências Tecnológicas e Ciências Econômicas, a fomentarem 
iniciativas de ensino, pesquisa e extensão que, indissociadas entre si, possam contribuir com a identificação de estratégias de orientação profissional e transição de estudantes universitários com deficiência para o mundo do trabalho.

Isso porque, conforme o presente artigo apresenta, há notável desarticulação entre universidade e mundo do trabalho e o espectro legislativo configura-se, na prática, como um simulacro de políticas que não garantem, efetivamente, a legitimação da participação dessa população em todas as esferas da sociedade.

As IES e as sociedades brasileiras, contudo, precisam ser incitadas a (re)organizarem-se para que esses acadêmicos sejam sujeitos de sua própria história, legitimando sua cidadania, em seus processos individuais de construção identitária, em um contexto socioeconômico, cultural, acadêmico, profissional e social preponderantemente competitivo e, por sua vez, discriminatório.

Compreendemos, portanto, que a orientação profissional para estudantes universitários com deficiência constitui-se como a inter-relação dinâmica, interdisciplinar e multivetorial de recursos humanos, materiais, didáticos, tecnológicos e financeiros. Importa que isso ocorra no processo de planejamento, desenvolvimento, implementação e avaliação processual a curto, médio e longo prazo, de estratégias curriculares, didáticas, gerenciais, administrativas e políticas. A orientação profissional prevê, ainda, o envolvimento transversal e concomitante de sujeitos e contextos das Instituições da Educação Superior e do mundo do trabalho, considerando-se as múltiplas identidades, diferenças e subjetividades, sob a perspectiva biopsicossocial.

Espera-se que o presente estudo contribua com as comunidades científicas e acadêmicas, bem como com as diversas esferas governamentais, administrativas e sociais no fomento às discussões, proposições e implementações de iniciativas que possibilitem o desenvolvimento acadêmico, profissional e cidadão dos estudantes universitários com deficiência, dos profissionais das diversas áreas do conhecimento, assim como da sociedade, sob a perspectiva biopsicossocial e inclusiva.

\section{Referências}

AGUIAR, Wanda Maria Junqueira; BOCK, Ana Maria Bahia; OZELLA, Sérgio. A orientação profissional com adolescentes: um exemplo de prática na abordagem sócio-histórica. In: BOCK, Ana Maria Bahia; GONÇALVES, Maria da Graça; FURTADO, Odair. (Org.),

Psicologia sócio-histórica: uma perspectiva crítica em psicologia. São Paulo: Cortez, 2009. 
http://dx.doi.org/10.5902/1984686X53123

ALFREDO, Raquel Antonio. Aproximações explicativas a partir da análise de sentidos e significados constituídos em espaços/momentos/situações de escolha na escola. (Dissertação de Mestrado). Programa de Pós-Graduação em Educação, Pontifícia Universidade Católica de São Paulo - PUC. 2006.

AMBIEL, Rodolfo Augusto Matteo; POLLI, Mariana Fralleti. Análise da produção científica brasileira sobre avaliação psicológica em Orientação Profissional. Estudos Interdisciplinares em Psicologia, Londrina, v. 2, n. 1, p. 103-121, jun. 2011.

ARENDT, Hanna. A condição humana. Rio de Janeiro: Forense Universitária, 2018.

BOTELHO, Louise Lira Roedel; CUNHA, Cristiano Castro de Almeida; MACEDO, Marcelo. O método da revisão integrativa nos estudos organizacionais. Gestão e Sociedade, v. 5, n. 11, p. 121-136, 2 dez. 2011.

BRASIL. Constituição da República Federativa do Brasil, de 5 de outubro de 1988.

Disponível em: http://www.planalto.gov.br/ccivil_03/constituicao/constituicao.htm. Acesso em: 23 set. 2020.

BRASIL. Decreto no 3.298, de 20 de dezembro de 1999. Regulamenta a Lei no 7.853, de 24 de outubro de 1989, que dispõe sobre a Política Nacional para a Integração da Pessoa Portadora de Deficiência, consolida as normas de proteção, e dá outras providências. Disponível em: https://www2.camara.leg.br/legin/fed/decret/1999/decreto-3298-20-dezembro1999-367725-norma-pe.html. Acesso em: 23 set. 2020.

BRASIL. Instituto Nacional de Estudos e Pesquisas Educacionais Anísio Teixeira (INEP). Diretoria de Estatísticas Educacionais. Censo da Educação Superior: microdados. Rio de Janeiro. Disponível em: http://portal.inep.gov.br/web/guest/microdados. Acesso em: 20 fev. 2020.

BRASIL. Lei no 5.692, de 11 de agosto de 1971. Fixa diretrizes e Bases para o ensino de $1^{\circ}$ e $2^{\circ}$ graus, e dá outras providências. Disponível em:

https://www2.camara.leg.br/legin/fed/lei/1970-1979/lei-5692-11-agosto-1971-357752-normapl.html. Acesso em: 23 set. 2020.

BRASIL. Lei no 8.213, de 24 de julho de 1991. Dispõe sobre os Planos de Benefícios da Previdência Social e dá outras providências. Disponível em:

http://www.planalto.gov.br/ccivil_03/leis/l8213cons.htm. Acesso em: 23 set. 2020.

BRASIL. Lei n. 9.394/96, de 20 de dezembro de 1996. Estabelece as Diretrizes e Bases da Educação Nacional. Disponível em: http://www.planalto.gov.br/ccivil_03/leis/l9394.htm. Acesso em: 23 set. 2020.

BRASIL. Lei no 13.146, de 6 de julho de 2015. Institui a Lei Brasileira de Inclusão da Pessoa com Deficiência (Estatuto da Pessoa com Deficiência). Disponível em:

http://www.planalto.gov.br/ccivil_03/_ato2015-2018/2015/lei/l13146.htm. Acesso em: 23 set. 2020. 
BRASIL. Ministério da Economia. 2019. Relação Anual de Informações Sociais [RAIS]. Disponível em: https://www.gov.br/economia/pt-br/assuntos/noticias/2019/02/contratacao-depessoas-com-deficiencia-bate-recorde-apos-fiscalizacao-do-trabalho. Acesso em: 29 jun. 2020.

BRASIL. Portal Educação. Consultor de Carreira: o que faz? Disponível em: https://www.portaleducacao.com.br/conteudo/artigos/conteudo/consultor/50651. Acesso em: 04 mar. 2019.

CABRAL, Leonardo Santos Amâncio; MENDES, Enicéia Gonçalves; ANNA, Lucia de. Orientação acadêmica e profissional dos estudantes com deficiência nas universidades italianas. Revista Ibero-Americana de Estudos em Educação, [S.I.], p. 615-630, ago. 2015.

CABRAL, Leonardo Santos Amâncio; SANTOS, Vivian; MENDES, Enicéia Gonçalves. Educação especial na educação superior: podemos falar em democratização do acesso? Educação e Fronteiras, Dourados, v. 8, n. 23, p. 111-126, ago. 2018.

CASTRO, Bianca Gomes da Silva Muylaert Monteiro; AMARAL, Shirlena Campos de Souza; BORGES, Luís Felipe Câmara. A inclusão da pessoa com deficiência no mercado de trabalho: perspectivas sobre a exclusão produtiva. Revista on line de Política e Gestão Educacional, [S.I.], p. 1433-1447, set. 2017.

CAVALCANTE, Roberta Maria Fernandes; RODRIGUES, Yangla Kelly Oliveira; NETTO, Raymundo. Enem Projeto de Vida: profissão e carreira. Fortaleza: Fundação Demócrito Rocha/Uane. 2015.

CHIAVENATO, Idalberto. Gestão de Pessoas: o novo papel dos recursos humanos nas organizações. São Paulo: Manole, 2014.

Department of Education and Science. Learning for Life: Paper on Adult Education. Dublin: Stationery Office. Commission of the European Communities: "Adult learning: It is never too late to learn". (2000). Disponível em: https://eur-lex.europa.eu/legalcontent/EN/ALL/?uri=CELEX:52006DC0614. Acesso em 23 set. 2020.

EGIDO GÁLVEZ, Inmaculada; CERRILLO MARTIÍN, Rosario; CAMINA DURANTES, Asunción. La inclusión social y laboral de las personas con discapacidad intelectual mediante los programas de empleo con apoyo. Un reto para la Orientación. REOP - Revista Española de Orientación y Psicopedagogía, [S.I.], v. 20, n. 2, p. 135-146. 2009.

GANONG, Lawrence. Integrative reviews of nursing research. Research in Nursing \& Health, v. 10, n. 11, p. 1-11. 1987.

GARCÍA, Maria Ángeles Segura; MARTÍNEZ-VICENTE, José Manuel; GARCÍA MARTÍNEZ, Isabel. Relación entre el desarrollo vocacional eficaz y los factores de elección en titulados universitarios con discapacidad activos laboralmente. Un estudio preliminar. REOP - Revista Española de Orientación y Psicopedagogía, [S.I.], v. 26, n. 3, p. 8-25, abr. 2015. 
GONZÁLEZ, Manuel Álvarez; GARCÍA, Maria Fe Sanchez. Concepto, evolución y enfoques teóricos de la orientación professional. In: GARCÍA, Maria Fe Sanchez; GONZÁLEZ, Manuel Álvarez (Org). Bases teórico-prácticas de la orientación profesional. Madrid: UNED, 4-48. 2012.

GUILLAMÓN, José Rafael; RODRIGUEZ, Víctor. Atención y orientación a los estudiantes con discapacidad en la UNED. REOP - Revista Española de Orientación y Psicopedagogía, [S.I.], v. 21, n. 2, p. 391-400, jan. 2014.

HOUAISS, Antonio. Dicionário Houaiss da Língua Portuguesa. Rio de Janeiro: Ed. Objetiva, 2001.

LEHMAN, Yvette Piha. Orientação profissional na pós-modernidade, In: LEVENFUS, Rosane Schotgues; SOARES, Dulce Helena Penna et al. (Org). Orientação Vocacional Ocupacional. Porto Alegre: Artmed, 2010.

ITÁLIA. Legge quadro no 104, 05 febbraio 1992. Legge-quadro per l'assistenza, l'integrazione sociale e i diritti delle persone handicappate. Disponível em: https://archivio.pubblica.istruzione.it/news/2006/allegati/legge104_92.pdf. Acesso em: 23 set. 2019.

LISBOA, Marilu. Orientação profissional e mundo do trabalho: reflexões sobre uma nova proposta frente a um novo cenário. In: LEVENFUS, Rosane Schotgues; SOARES, Dulce Helena Penna (Org.) Orientação vocacional ocupacional: novos achados teóricos, técnicos e instrumentais para a clínica, a escola e a empresa. Porto Alegre: Art Med, 2002.

LLEDÓ, Gonzalo Lorenzo; CARRERES, Asunción Lledó; LLEDÓ, Alejandro Lorenzo; VERA, Graciela Arráez. La acción tutorial como acompañamiento en el alumnado universitário con discapacidad: hacia una educación inclusiva. International Journal of Developmental and Educational Psychology, v. 4, n. 1, p. 137-144. 2017.

MELNYK, Bernadette Mazurek; FINEOUT-OVERHOLT, Ellen; STILLWELL, Susan; WILLIAMSON, Kathleen. The Seven Steps of Evidence-Based Practice: Following this progressive, sequential approach will lead to improved health care and patient outcomes. American Journal of Nursing, v. 110, n. 1, p. 51-53. 2010.

MELO-SILVA, Lucy Leal. Ética e competência na prática da orientação profissional. In: MELO-SILVA, Lucy Leal; SANTOS, Manoel Antonio; SIMÕES, Joab Tenysson; AVI, Maria Cecília. Orientação profissional: teoria e prática - Arquitetura de uma ocupação. São Paulo: Vetor, p. 69-90. 2003.

MELO-SILVA, Lucy Leal; LASSANCE, Maria Célia Pacheco; SOARES, Dulce Helena Penna. A orientação profissional no contexto da educação e trabalho. Revista Brasileira de Orientação Profissional, São Paulo, v. 5, n. 2, p. 31-52, dez. 2004.

NAG, Sonali. Re-thinking support: the hidden school-to-work challenges for individuals with special needs. International Journal of Educational Vocational Guidance, v. 11, p. 125137, jun. 2011. 
NELSON, Theodor Holm. A file structure for the complex: the changing and the indeterminate. In: Proceedings of the ACM 20th National Conference. 1965. pp. 84-100.

NÉRICE, Imideo Giuseppe. Introdução à orientação educacional. 5aㅡ Ed. São Paulo: Atlas, 1992.

PINTO, Telma Maranhão Gomes; CASTANHO, Marisa Irene Siqueira. Sentidos da escolha e da orientação profissional: um estudo com universitários. Estud. psicol., v. 29, n. 3, p. 395413, set. 2012.

ROTHER, Edna Terezinha. Revisão sistemática x revisão narrativa. Acta Paul. enferm. São Paulo, v. 20, n. 2, p. 5-6, jun. 2007.

SÁNCHEZ, Maria Tamara Polo; JUSTICIA, Maria Dolores López. Transición al mundo laboral de estudiantes universitarios con discapacidad: experiencia de un programa formativo. REOP - Revista Española de Orientación y Psicopedagogía, [S.I.], v. 22, n. 3, p. 302-313, jan. 2014.

SOARES, Dulce Helena. O que é Orientação Profissional. São Paulo: Editora Brasiliense, 2009.

THE ECONOMIST. (2017, janeiro 14). Lifelong learning: how to survive in the age of automation - a special report. Equipping people to stay ahead of technological change. The Economist, Londres, Caderno 2, 1-8. Disponível em:

https://learnmore.economist.com/story/585a4c7289933e0042490f8d/. Acesso em: 23 set. 2020.

WHITEMORE, Robin; KNAFL, Kathleen. The integrative review: updated methodology. Journal of Advanced Nursing, v. 52, n. 5, p. 546-553, dez. 2005.

\section{Notas}

${ }^{1}$ Cidadania ativa é o exercício dos direitos e deveres civis, políticos e sociais estabelecidos na Constituição de um país por parte dos seus respectivos cidadãos (indivíduos que compõem determinada nação) (ARENDT, 2018).

2 Compõem o bojo das IES em questão aquelas pertencentes às esferas administrativas Pública Federal; Pública Estadual; Pública Municipal; Privada com fins lucrativos; Privada sem fins lucrativos e Especial.

${ }^{3}$ Adotaremos o termo deficiências (no plural), por compreendermos que uma pessoa nessa condição pode ter duas ou mais deficiências associadas. O Decreto n 5.296 de 2 de dezembro de 2004 fazia menção a essa condição como deficiência múltipla. Contudo, em 2015, a Lei Brasileira de Inclusão (Estatuto da Pessoa com Deficiência), demarca que pessoa com deficiência é aquela "que tem impedimento de longo prazo de natureza física, mental, intelectual ou sensorial” (BRASIL, 2015, Art. $2^{\circ}$, grifo dos autores), invisibilizando a condição de associação entre duas ou mais deficiências.

${ }^{4}$ De acordo com González e Garcia (2012), o primeiro refere-se especificamente à escolha do trabalho aspirado, enquanto que o segundo abrange a manutenção ou processos para a troca do emprego. 
http://dx.doi.org/10.5902/1984686X53123

${ }^{5}$ Segundo Nérice (1992), no ano de 1930, inicia-se um serviço de sistematização de seleção, orientação e formação de aprendizes nas oficinas da Estrada de Ferro Sorocabana. Em 1931, foi criado o primeiro Serviço Público de Orientação Profissional no Brasil em São Paulo e, em 1938, o Instituto Nacional de Estudos Pedagógicos (INEP) criou uma subdivisão, em âmbito nacional, para implantar a orientação educacional que se referia ao conhecimento do indivíduo, a orientação profissional e a formação integral da personalidade como um todo. Além disso, no Rio de Janeiro, em 1947, foi criado o Instituto de Seleção e de Orientação Profissional [ISOP] (1947). Ainda segundo a autora, com o objetivo de estimular a formação dos orientadores em cursos de nível superior, foram realizados três simpósios nacionais (1957-1958-1960) e seminários regionais que focalizaram e discutiram os principais aspectos teóricos e práticos da orientação.

${ }^{6} \mathrm{O}$ termo integrativa tem origem na integração de opiniões, conceitos, métodos e/ou ideias provenientes das pesquisas utilizadas na referida abordagem com potencial para construir ciência e, até mesmo, desenvolver teorias (WHITEMORE; KNAFL, 2005).

${ }^{7}$ Os operadores booleanos, ferramentas para busca avançada, são fundamentais para o critério de inclusão. Na prática, se não forem utilizados ou utilizar-se apenas um deles, o número de artigos encontrados pode variar significativamente, interferindo no resultado final da amostra.

${ }^{8}$ Pubmed, Pepsic, PsycINFO, Eric, SciELO, Coordenação de Aperfeiçoamento de Pessoal de Ensino Superior [CAPES] e Sistema de Información Científica Red de Revistas Científicas de América Latina y el Caribe, España y Portugal [REDALYC].

${ }^{9}$ Dos cinco artigos em língua espanhola, quatro eram provenientes do mesmo periódico científico: Revista Española de Orientación y Psicopedagogía.

10 Nome do Periódico; Título do Artigo; Autor; Ano; Tema Principal; Objetivo Geral; Objetivos Específicos; Método; Principais Resultados; Excertos Relevantes; e Conclusões.

11 A Constituição Federal de 1988; o Aviso Circular do Ministério da Educação no 277/1996; a Lei no 9.394/1996 (e sua redação dada pela Lei no 12.796/2013); a Portaria Ministerial $n^{\circ}$ 1.120/1999); o Decreto no 3.956/2001; a Lei oㅡ 10.436/2002; a Portaria o․ 2.678/2002; a Portaria oㅡ 3.284/2003 (que substituiu a Portaria no 1.679/1999 e enumera os referenciais de acessibilidade na Educação Superior; a Associação Brasileira de Normas Técnicas [ABNT]/NBR 9.050/2004; o Decreto Federal o 5.296/2004; o Decreto no 5.626/2005; o Programa de Acessibilidade na Educação Superior (2005) e seus documentos orientadores; o Plano de Desenvolvimento da Educação/2007; a Política Nacional de Educação Especial na Perspectiva da Educação Inclusiva/2008); o Decreto no 6.949/2009; o Decreto no 7.234/2010, que dispõe sobre o Programa Nacional de Assistência Estudantil [PNAES]; o Decreto № 7.611/2011; a Lei oㅜ 12.711/2012 (modificada pela Lei oㅡ 13.409/2016); a Portaria Normativa ํㅡ 18/2012; o Decreto no 12.764/2012; os Referenciais de Acessibilidade na Educação Superior e a Avaliação in loco do Sistema Nacional de Avaliação da Educação Superior (2013); a Lei no 13.416/2015, que Institui a Lei Brasileira de Inclusão da Pessoa com Deficiência (Estatuto da Pessoa com Deficiência).

${ }^{12}$ A Lei 8.112 (1990) que assegura, nos concursos públicos, até 20\% das vagas para pessoas com deficiência; a Lei 8.213 (1991), que dispõe percentuais de vagas para pessoas com deficiência nas empresas com mais de 100 funcionários, variando de $2 \%$ a $5 \%$, conforme o número total de empregados; o Decreto Federal ํ․ 3.298 (1999), que regulamenta as leis anteriores e realça tanto a questão do ingresso em concurso público, estabelecendo percentual mínimo para reserva de vagas para os mesmos, quanto às cotas nas empresas privadas; o Decreto 5296 (2004); o Programa Nacional de Acesso ao Ensino Técnico e Emprego [PRONATEC]/Viver sem Limites (2013) e a Lei no 13.146 (2015), que dispõe sobre o Estatuto da Pessoa com Deficiência.

${ }^{13}$ Segundo Houaiss (2001) e o Portal Educação (2019), tutores e conselheiros, no âmbito do processo de orientação profissional, apresentam algumas diferenças em suas conceitualizações. Enquanto Conselheiros de carreira da universidade (counselor) visam a estimular as capacidades pessoais e profissionais do sujeito ao longo da trajetória acadêmica, auxiliando o futuro profissional a externar as suas principais qualidades e pontos de melhora, por meio de um olhar imparcial e impessoal, os Tutores supervisionam, dirigem e gerenciam a instrução ou orientação de outros alunos. 


\section{Correspondência}

Liz Amaral Saraiva Morgado - Instituto Federal do Paraná, Rua João XXIII, 600, Judith, Londrina, Paraná -- Brasil

CEP: $86060-370$

\section{(c) $($ ) $(9)$} International (CC BY-NC 4.0) 